series, of which this is the first volume, is also welcome. The book provides a beginning but it also demonstrates how far the field of bioethics has progressed in its expectations of rigorous and balanced debate.

\section{RACHEL BARTLETT}

Formerly Deputy Director, Nuffield Council on Bioethics

\section{Access to the Genome: The Challenge to Equality}

\author{
Maxwell J Mehlman and Jeffrey $\mathbf{R}$ \\ Botkin, Washington DC, Georgetown \\ University Press, 1998, 152 pages, \\ £11-75, US\$14-95.
}

This engaging and accessible book focuses on some of the broader social and economic implications of the Human Genome Project. It begins with a solid description of basic genetics and the Genome Project itself, and follows up with chapters on the practical applications of genetic information (in brief, genetic tests, gene therapies and genetic enhancement) and the impact such technologies might have, But these are just the warm-up for the core of the book which looks at the way genetic technologies might impact upon health care systems, and on society as a whole.

In the chapter "Access to genetic technologies" the authors address issues such as supply shortages, insurance coverage and access to genetic technologies via ability to pay with the use of both historical and contemporary examples from health care. Using cases such as debates around access to dialysis in the 1960s and the attempt by the US state of Oregon to increase the numbers of people covered by state health care by reducing the range of treatments paid for, the authors conclude that the general availability of genetic technologies is likely to be extremely limited due to the prohibitive cost. An important point about this chapter (and much of the rest of the book as well) is that it is written from a US position, ie there is in-depth discussion of the ins and outs of US private health insurance legislation, but no mention of life insurance, which is of far more relevance to the UK (and other, non-US countries). This is not a criticism of the book (which makes potentially esoteric and obscure legal issues quite readable), but a warning for potential readers perhaps looking for a broader discussion of the concept of insurance as a whole.

Chapter 6, "Genetic technologies and the challenge to equality", is far more broadly relevant in that the authors suggest that genetic technologies present a threat to the foundations of most Western democratic societies. Initially they work thorough classic political/ethical theories (such as Utilitarianism and Rawlsian Justice), and look at how these theories would address the inequality which would stem from expensive genetic technologies only being available to wealthy individuals. They point out that such wealth-based access to these technologies could ossify social differences in society, with those unable to pay for such technologies (including genetic enhancement) and their children suffering in terms of job security and income as an enhanced "genetic aristocracy" took control. Such a situation prevents what Mehlman and Botkin regard as one of the most important values in a democratic society; the chance to be upwardly mobile; "If the reduction in upward mobility were substantial enough, the lower classes, who could not afford to better themselves genetically, would remain locked into their genetic class"(page 102). The authors foresee various socially damaging consequences to this erosion of equality, but accept that they may be overpessimistic, the "equivalent to Chicken Little alarming the barnyard due to a genetic acorn" (page 105). Personally I think that they argue persuasively for their worst case scenario, and propose an intriguing solution.

They consider total prohibition on genetic research and technologies, but having looked at the "war on drugs" and other examples, correctly conclude that such action does little in the long run. Their solution to the problem of genetic inequality is a genetic lottery "open to anyone, but everyone would have the same chance of winning" (page 125). Those who objected to the use of such technologies could opt out, but it would give those people who could never afford to buy genetic enhancements or gene therapy, the possibility of leapfrogging any genetic class barriers. Intriguing and original as this idea is, the difficulties do seem rather obvious. If genetic technologies, why not other medical treatment? The authors would argue that genetic information is special, and hence genetic technologies more powerful than other medical treatments. Even allowing this, it would seem that the authors would have to defend the use of genetic enhancement technologies by a lottery winner to produce a son tall enough to play professional basketball, while denying gene therapy to a non-lottery winner's child. The lottery system (as presented, though perhaps not in all forms) fails to distinguish between those who need to win on medical grounds, and those who would like to win for more "cosmetic" reasons. The line between genetic therapy and enhancement is notoriously difficult to define, yet the authors do not seem to appreciate that such a lottery would at least have to make some distinction (however arbitrary), if it were to be, not just egalitarian (we're all equal before the dice) but also ethical.

A broader problem with the book is the underlying assumption that genetic information is all powerful. Although not as "triumphalist" as many others writing in this area, the authors' arguments and scenarios do depend on a rather deterministic view of human genetics, to the almost total exclusion of environmental influences. Despite this, the book is highly recommended to the interested reader and perhaps as a course book.

ADAM M HEDGECOE

Department of Science and Technology Studies, UCL, London

\section{Deciding Who Lives}

Renee Anspach, California, University of California Press, 1997, 303 pages, $£ 12.95$ (sc).

Deciding Who Lives is an analysis of the practice of medical ethical decision making in the neonatal intensive care nursery. As stated, the book seeks to study not philosophical principles of bioethics, but rather the practicality and reality of implementing these principles. Both the strengths and the weaknesses of this study emanate from the author's basic lack of active participation in the field.

As an outside observer of the intensive care nursery environment, the author is able to make some refreshing observations, unencumbered by the professional biases to which those of us working in the field are subject. I found her comparative analysis of the differential observations of doctors $v$ nurses, and the implications thereof particularly fascinating. There is much that we as practitioners can learn from 